\title{
More research is required to understand factors influencing antibiotic prescribing in complex conditions like suspected ventilator-associated pneumonia
}

Thomas P. Hellyer ${ }^{1}$, Daniel F. McAuley ${ }^{2}$, Timothy S. Walsh ${ }^{3}$, Niall Anderson ${ }^{3}$, Andrew Conway Morris ${ }^{4}$, Suveer Singh ${ }^{5}$, Paul Dark ${ }^{6}$, Alistair I. Roy ${ }^{7}$, Gavin D. Perkins ${ }^{8}$, Ronan McMullan ${ }^{2}$, Lydia M. Emerson ${ }^{2}$, Bronagh Blackwood $^{2}$, Stephen E. Wright ${ }^{9}$, Kallirroi Kefala ${ }^{10}$, Cecilia M. O'Kane ${ }^{2}$, Simon V. Baudouin ${ }^{1}$, Ross L. Paterson ${ }^{11}$, Anthony J. Rostron ${ }^{1}$, Ashley Agus ${ }^{12}$, Jonathan Bannard-Smith ${ }^{13}$, Nicole M. Robin ${ }^{14}$, Ingeborg D. Welters ${ }^{15}$, Christopher Bassford ${ }^{16}$, Bryan Yates ${ }^{17}$, Craig Spencer ${ }^{18}$, Shondipon K. Laha ${ }^{19}$, Jonathan Hulme $^{20}$, Stephen Bonner ${ }^{21}$, Vanessa Linnett ${ }^{22}$, Julian Sonksen ${ }^{23}$, Tina Van Den Broeck ${ }^{24}$, Gert Boschman $^{24}$, D. W. James Keenan ${ }^{24}$, Jonathan Scott ${ }^{1}$, A. Joy Allen ${ }^{1}$, Glenn Phair ${ }^{12}$, Jennie Parker ${ }^{1}$, Susan A. Bowett ${ }^{1}$, A. John Simpson ${ }^{1 \wedge}$

${ }^{1}$ Faculty of Medical Sciences, Newcastle University, Newcastle, UK; ${ }^{2}$ The Wellcome-Wolfson Centre for Experimental Medicine, Queen's University, Belfast, UK; ${ }^{3}$ College of Medicine and Veterinary Medicine, University of Edinburgh, Edinburgh, UK; ${ }^{4}$ Department of Medicine, University of Cambridge, Cambridge, UK; ${ }^{5}$ Department of Cancer and Surgery, Imperial College, London, UK; ${ }^{6}$ Manchester National Institute for Health Research Biomedical Research Centre, University of Manchester, Manchester, UK; ${ }^{7}$ Integrated Critical Care Unit, Sunderland Royal Hospital, Sunderland, UK; ${ }^{8}$ Warwick Medical School, University of Warwick, Warwick, UK; ${ }^{9}$ Newcastle upon Tyne Hospitals NHS Foundation Trust, Newcastle, UK; ${ }^{10}$ Intensive Care Unit, Royal Infirmary of Edinburgh, Edinburgh, UK; ${ }^{11}$ Intensive Care Unit, Western General Hospital, Edinburgh, UK; ${ }^{12}$ Northern Ireland Clinical Trials Unit, Belfast, UK; ${ }^{13}$ Intensive Care Unit, Manchester Royal Infirmary, Manchester, UK; ${ }^{14}$ Countess of Chester Hospital NHS Foundation Trust, Chester, UK; ${ }^{15}$ Institute of Ageing and Chronic Disease, University of Liverpool, Liverpool, UK; ${ }^{16}$ Intensive Care Unit, University Hospital Coventry, Coventry, UK; ${ }^{17}$ Intensive Care Unit, Northumbria Specialist Emergency Care Hospital, Cramlington, UK; ${ }^{18}$ Intensive Care Unit, Cardiff and Vale University Health Board, Cardiff, UK; ${ }^{19}$ Lancashire Teaching Hospitals NHS Foundation Trust, Preston, UK; ${ }^{20}$ Sandwell and West Birmingham Hospitals NHS Trust, Birmingham, UK; ${ }^{21}$ Intensive Care Unit, James Cook University Hospital, Middlesbrough, UK; ${ }^{22}$ Intensive Care Unit, Queen Elizabeth Hospital, Gateshead, UK; ${ }^{23}$ Dudley Group NHS Foundation Trust, Dudley, $\mathrm{UK} ;{ }^{24}$ Becton Dickinson Life Sciences, Erembodegem, Belgium

Correspondence to: John Simpson. Faculty of Medical Sciences, Newcastle University, Newcastle, UK.

Email: j.simpson@ncl.ac.uk.

Provenance and Peer Review: This article was commissioned by the editorial office, Annals of Translational Medicine. The article did not undergo external peer review.

Response to: Yoshimura J, Hashimoto H, Yamakawa K. Antibiotic stewardship in critically ill patients with suspected ventilator-associated pneumonia. Ann Transl Med 2020. doi: 10.21037/atm-20-2421

Submitted May 16, 2020. Accepted for publication Jun 18, 2020.

doi: $10.21037 /$ atm-20-3701

View this article at: http://dx.doi.org/10.21037/atm-20-3701

We read with interest the commentary by Yoshimura et al. in relation to our recently published trial investigating whether a novel, rapid biomarker-based rule-out of ventilator-associated pneumonia (VAP) could improve antibiotic stewardship (1).
Antimicrobial resistance is a growing global crisis and strategies that aim to improve antibiotic stewardship are urgently needed (2). Critically ill patients are at high-risk of developing healthcare-associated infections and receive a high burden of antibiotics $(3,4)$. The diagnosis of VAP is

^ ORCID: 0000-0003-4731-7294 
challenging as clinical and radiological features are nonspecific, with $30-60 \%$ of patients with suspected VAP ultimately having infection confirmed (5-8). Respiratory sampling techniques can have a significant impact on the VAP rate observed, with a diagnostic approach based on endotracheal aspirate seeming to provide far higher false positive rates than an approach based on invasive bronchoscoping sampling (9). Moreover, at least in some important studies, a bronchoscopic approach has been associated with less antibiotic use, less antimicrobial resistance, and no signal of harm $(10,11)$.

Our work aimed to address the overuse of antibiotics for VAP through the development of novel diagnostics. Our trial followed previous single-centre derivation and multi-centre validation studies $(12,13)$. Yoshimura et al. highlight three potential areas that might explain the similar antibiotic use observed in the two groups we studied (one having a biomarker-based recommendation on antibiotic use, the other routine care). These centred on the quality of bronchoalveolar lavage (BAL), the low proportion of patients with low biomarker levels in the intervention group, and the low compliance with a recommendation to stop antibiotics when biomarkers confidently suggested VAP was absent. These will be considered in turn.

The assay failures in our trial, pointed out by Yoshimura et al., actually related to use of the diagnostic assay. This was due to technical issues as a research assay was adopted into hospital laboratories. Although there is considerable variation in the use of bronchoscopy for the diagnosis of VAP in the UK (14), bronchoscopy is still a common procedure in intensive care units. In our study BAL was performed to a standard operating procedure, often by experienced bronchoscopists. Consistent performance of the biomarker-test across our studies suggests to us that BAL was performed to a consistently high standard.

Yoshimura and colleagues are correct in saying that, in our intervention group, there were fewer "low biomarker" results than anticipated. The trial was powered based on a modelled change in the frequency distribution of antibioticfree days in the 7 days following BAL (15), and not on the diagnostic performance of the biomarker or the expected number of patients with a rule-out test. The trial did retain adequate statistical power to detect a difference in antibiotic use, had there been adequate compliance with biomarkerguided recommendations.

While we believe the technical issues discussed above did not significantly influence the result of our trial, we completely agree with the authors that complex clinical and behavioural determinants were responsible for noncompliance with biomarker-guided recommendations, and ultimately for the similar, high use of antibiotics in each group. Our trial incorporated a process evaluation that captured some of this complexity. The study points to an important disconnect between clinicians' stated intentions and their prescribing practice which, in our experience, was sufficient to obviate the potential benefits of a good diagnostic test. Our study suggests that considerable work needs to be done to understand these complex behavioural issues and prescribing influences, if diagnostic tests are to have a greater chance of influencing outcomes in conditions like suspected VAP.

Yoshimura and colleagues are conducting an important trial seeking to optimise antibiotic use through Gram stain of respiratory samples. Data suggest that the use of endotracheal aspirates (rather than BAL) may actually result in more antibiotic use (9). While Gram stain may result in a narrower spectrum of antibiotics, it will be very interesting to see whether the total number of days of antibiotics can be reduced. If there is room to add a process evaluation within the time-frame of their trial, our experience suggests it may yield valuable insights. We wish the authors every success with their trial, we very much hope it can deliver benefits to patients with VAP, and we look forward to the results.

\section{Acknowledgments}

Funding: The study was supported by Health Innovation Challenge Fund (HICF-510-078; 094949/Z/10/X), a parallel funding partnership between the Department of Health and Wellcome Trust. The views expressed in this publication are those of the authors and not necessarily those of the Department of Health or Wellcome Trust. The study was also supported by the NIHR Newcastle Biomedical Research Centre (IS-BRC-1215-20001).

\section{Footnote}

Conflicts of Interest: All authors have completed the ICMJE uniform disclosure form (available at http://dx.doi. org/10.21037/atm-20-3701). PD reports advisory board membership with DNAelectronics Ltd., and grants from the UK NIHR in relation to infection and sepsis diagnosis and 
treatment outside the current work; ACM reports he is a member of the advisory board of Serendex pharmaceuticals; SS reports personal fees from Ambu Ltd. outside the submitted work; TSW reports grants from the Wellcome Trust/NIHR during the conduct of the study; CMO reports grants from the Wellcome Trust and NIHR during the conduct of the study, and her spouse has received personal fees from consultancy for GlaxoSmithKline, Bayer, and Boehringer Ingelheim, outside the submitted work; TVDB, GB and DWJK were employees of Becton Dickinson \& Company, during the original work in the trial; AJS reports grants from the Wellcome Trust and the NIHR for the conduct of the study, his institution has received funds from grants from NIHR, MRC and others, outside the submitted work; AJS is Director of the NIHR Newcastle Medtech and In Vitro Diagnostics Co-operative. DFM reports a grant from the Wellcome Trust and NIHR for the conduct of the study. Outside the submitted work, DFM reports personal fees from consultancy for GlaxoSmithKline, Boehringer Ingelheim and Bayer. In addition, his institution has received funds from grants from the UK NIHR, Wellcome Trust, Innovate UK and others. DFM is a Director of Research for the Intensive Care Society and NIHR EME Programme Director. The authors have no other conflicts of interest to declare.

Ethical Statement: The authors are accountable for all aspects of the work in ensuring that questions related to the accuracy or integrity of any part of the work are appropriately investigated and resolved.

Open Access Statement: This is an Open Access article distributed in accordance with the Creative Commons Attribution-NonCommercial-NoDerivs 4.0 International License (CC BY-NC-ND 4.0), which permits the noncommercial replication and distribution of the article with the strict proviso that no changes or edits are made and the original work is properly cited (including links to both the formal publication through the relevant DOI and the license). See: https://creativecommons.org/licenses/by-nc-nd/4.0/.

\section{References}

1. Hellyer TP, McAuley DF, Walsh TS, et al. Biomarkerguided antibiotic stewardship in suspected ventilatorassociated pneumonia (VAPrapid2): a randomised controlled trial and process evaluation. Lancet Respir Med 2020;8:182-91.

2. Laxminarayan R, Duse A, Wattal C, et al. Antibiotic resistance-the need for global solutions. Lancet Infect Dis 2013;13:1057-98.

3. Brusselaers N, Vogelaers D, Blot S. The rising problem of antimicrobial resistance in the intensive care unit. Ann Intensive Care 2011;1:47.

4. Magill SS, Edwards JR, Bamberg W, et al. Multistate point-prevalence survey of health care-associated infections. N Engl J Med 2014;370:1198-208.

5. Chastre J, Fagon JY. Ventilator-associated pneumonia. Am J Respir Crit Care Med 2002;165:867-903.

6. Ego A, Preiser JC, Vincent JL. Impact of diagnostic criteria on the incidence of ventilator-associated pneumonia. Chest 2015;147:347-55.

7. Schoemakers RJ, Schnabel R, Oudhuis GJ, et al. Alternative diagnosis in the putative ventilator-associated pneumonia patient not meeting lavage-based diagnostic criteria. Scand J Infect Dis 2014;46:868-74.

8. Loftus TJ, Lemon SJ, Nguyen LL, et al. Early bronchoalveolar lavage for intubated trauma patients with TBI or chest trauma. J Crit Care 2017;39:78-82.

9. Conway Morris A, Kefala K, Simpson AJ, et al. Evaluation of the effect of diagnostic methodology on the reported incidence of ventilator-associated pneumonia. Thorax 2009;64:516-22.

10. Fagon JY, Chastre J, Wolff M, et al. Invasive and noninvasive strategies for management of suspected ventilator-associated pneumonia. A randomized trial. Ann Intern Med 2000;132:621-30.

11. Raman K, Nailor MD, Nicolau DP, et al. Early antibiotic discontinuation in patients with clinically suspected ventilator-associated pneumonia and negative quantitative bronchoscopy cultures. Crit Care Med 2013;41:1656-63.

12. Conway Morris A, Kefala K, Wilkinson TS, et al.

Diagnostic importance of pulmonary interleukin-1beta and interleukin-8 in ventilator-associated pneumonia. Thorax 2010;65:201-7.

13. Hellyer TP, Morris AC, McAuley DF, et al. Diagnostic accuracy of pulmonary host inflammatory mediators in the exclusion of ventilator-acquired pneumonia. Thorax 2015;70:41-7.

14. Browne E, Hellyer TP, Baudouin SV, et al. A national survey of the diagnosis and management of suspected ventilator-associated pneumonia. BMJ Open Respir Res 
2014;1:e000066.

15. Hellyer TP, Anderson NH, Parker J, et al. Effectiveness of biomarker-based exclusion of ventilator-acquired pneumonia to reduce antibiotic use (VAPrapid-2):

study protocol for a randomised controlled trial. Trials 2016;17:318.
Cite this article as: Hellyer TP, McAuley DF, Walsh TS, Anderson N, Conway Morris A, Singh S, Dark P, Roy AI, Perkins GD, McMullan R, Emerson LM, Blackwood B, Wright SE, Kefala K, O’Kane CM, Baudouin SV, Paterson RL, Rostron AJ, Agus A, Bannard-Smith J, Robin NM, Welters ID, Bassford C, Yates B, Spencer C, Laha SK, Hulme J, Bonner S, Linnett V, Sonksen J, Van Den Broeck T, Boschman G, Keenan DWJ, Scott J, Allen AJ, Phair G, Parker J, Bowett SA, Simpson AJ. More research is required to understand factors influencing antibiotic prescribing in complex conditions like suspected ventilator-associated pneumonia. Ann Transl Med 2020;8(13):840. doi: 10.21037/atm-20-3701 